\title{
Chinese translation of strengths and difficulties questionnaire requires urgent review before field trials for validity and reliability Teck-Hock Toh*1, Sing-Jill Chow ${ }^{1}$, Tzer-Hwu Ting ${ }^{2}$ and Jill Sewell ${ }^{3}$
}

\begin{abstract}
Address: ${ }^{1}$ Fellow, Centre for Community Child Health, The Royal Children's Hospital, Parkville, Victoria, 3052, Australia, ${ }^{2} \mathrm{Fellow}$, Department of Endocrinology, The Royal Children's Hospital, Parkville, Victoria, 3052, Australia and ${ }^{3}$ Consultant Paediatrician, Centre for Community Child Health, The Royal Children's Hospital, and Principal Fellow, Faculty of Medicine, Dentistry and Health Sciences, University of Melbourne, Parkville, Victoria, 3052, Australia
\end{abstract}

Email: Teck-Hock Toh* - thtoh@yahoo.com; Sing-Jill Chow - sing-jill.chow@rch.org.au; Tzer-Hwu Ting - tzerhwuting@yahoo.com; Jill Sewell - jill.sewell@rch.org.au

* Corresponding author

Published: 15 August 2008

Child and Adolescent Psychiatry and Mental Health 2008, 2:23 doi:10.1 I86/1753-2000-2-23

This article is available from: http://www.capmh.com/content/2/I/23

(c) 2008 Toh et al; licensee BioMed Central Ltd.

This is an Open Access article distributed under the terms of the Creative Commons Attribution License (http://creativecommons.org/licenses/by/2.0), which permits unrestricted use, distribution, and reproduction in any medium, provided the original work is properly cited.
Received: 10 July 2008

Accepted: 15 August 2008

\begin{abstract}
: Strengths and Difficulties Questionnaire (SDQ) is a brief behavioural screening questionnaire for children and teenagers aged 3 to 16 years. It is available in 66 languages, and gaining more popularity world wide. Chinese translation of SDQ is available and has been used in clinical practice and research. We undertook the exercise to back-translate the current Chinese translation and it showed a number of differences compared to the original English SDQ. The differences and concerns include: (I) the flow and grammar of Chinese translation as well as wrongly written Chinese characters; (2) translated words that have deviated from the original meaning; (3) significant numbers of wording that are somewhat different from the original English version; (4) addition of auxiliary verbs that do not exist in original English version; and (5) the current Chinese $\mathrm{SDQ}$ is a general questionnaire for all age groups that does not observe the differences of wording that exist in the English versions.
\end{abstract}

Conclusion: An accurate translated Chinese version is important for researchers, clinicians and educators who work in the Chinese communities. There is an urgent need to review the translation of the Chinese SDQ version before more studies use it in the field.

\section{Full Text}

The results of a study in China on the validity, reliability and normative scores of a Chinese translation of the Strengths and Difficulties Questionnaire (SDQ) were recently published in your online journal on 29 April 2008 by Du et al [1]. Findings on psychometric properties were mixed, especially in the areas of peer problems and self-rating by adolescents. Concern was also raised about the validity of the Chinese translation. This does not surprise us because we believe the answers lie in the Chinese translation of the SDQ.
The SDQ is a brief behavioural screening questionnaire for children and teenagers aged 3 to16 years [2]. It was first tested in the United Kingdom and copy-righted by Goodman in 1997 [3]. Several versions are available and each version may include one to three of the following: a) 25-item psychological attributes, b) 5-question impact supplement, and c) seven follow-up questions. It is available in 66 languages, which include three English versions for the USA, United Kingdom and Australia that differ slightly in the wording used and age specification http:// www.sdqinfo.com/b3.html[2]. 
The Centre for Clinical Trials and Epidemiological Research at the Chinese University of Hong Kong and Iris Tan Mink had contributed greatly in the translation, backtranslation and validation of the Chinese version http:// www.sdqinfo.com/d4a.html[2]. Currently the Chinese translation has three versions available for parent, teacher and student respectively and each version consists of the 25-item psychological attributes and impact supplement only. They were presumably translated from the United Kingdom's English version because the wording matches more closely than the other English versions [2]. It is available in traditional form of Chinese writing, commonly used in Hong Kong and Taiwan. Chinese communities in China and South East Asian countries use the simplified form of writing.

Kou J, Du Y and Xia L published an article in Chinese in 2005 which concluded that the Chinese SDQ can be used to assess children and adolescents in Shanghai. This was derived from a validity and reliability study involving parents of 2128 students, using the three versions of Chinese SDQ and a retest 6 weeks later involving 47 of these parents [4].

Despite reported findings by Du Y and Kou J [1,4], we feel strongly that the current Chinese translation of SDQ has a number of differences compared to the original English SDQ. It is challenging and unscientific to compare any finding as a result of using two questionnaires with different languages and meaning. We therefore question the conclusion by Du Y et al about the use of Chinese version of SDQ in China.

We recognize that translation of scientific and clinical materials is not an easy task. We believe much effort has been put forward in the first translation by people in the Chinese University of Hong Kong and Iris Tan Mink. Their contribution should be recognized and appreciated. However, the current Chinese translation of SDQ should be critically appraised and reviewed to provide a more accurate translated Chinese version of SDQ that is reliable for its users in the field.

An exercise was undertaken by two authors of this letter (Toh TH and Ting TH) to back-translate the current Chinese SDQ independently. Ting TH had no prior knowledge of the SDQ before the translation. Both backtranslations were similar, and they are presented in Additional files 1,2 and 3. The differences and concerns we found are as follow:

1. The flow and grammar of the current Chinese SDQ are not smooth, with wrongly written Chinese characters.
2. Some translated word has deviated from the original meaning.

3. Significant numbers of wording, which include the word "True", used as the answer of all the 25 items, are somewhat different from the original UK English version.

4. Auxiliary verb "will", "can" and "very" were added in many of the 25-item psychological attributes and the significance of adding these verbs is unclear.

5. The current Chinese SDQ is a general questionnaire for all age groups, and does not observe some differences of wording that exists in the English versions.

Examples and explanation of these major differences and concerns are included in Table 1.

An online search on 12 June 2008, involving PsycINFO 1806, Ovid MEDLINE(R) 1996, CINAHL 1982 and EMBASE 1996 using "SDQ or Strengths and Difficulties Questionnaire" and "Chinese or Mandarin or China or Taiwan or Hong Kong" as key words have shown numerous publications quoting the use of SDQ Chinese translations in China and Hong Kong. It was used as a measurement tool for interventional trials $[5,6]$ and descriptive epidemiological studies $[7,8]$. Clinicians have also used it as a screening tool to prioritise psychiatry services [9] and to compare findings on psychometric properties of parent ratings on the Chinese version of the Swanson, Nolan, and Pelham IV scale [10].

\section{Conclusion}

It is obvious that SDQ will gain increasing popularity world wide, and an accurate translated Chinese version is important for researchers, clinicians and educationists who work in the Chinese population. There is an urgent need to review the translation of the Chinese SDQ version before more studies use it in the field. A more complete set of Chinese SDQ versions in both traditional and simplified Chinese forms of writing should be made available on the SDQ website. 
Table I: Summary of differences found between original english (UK) SDQ and Chinese translation

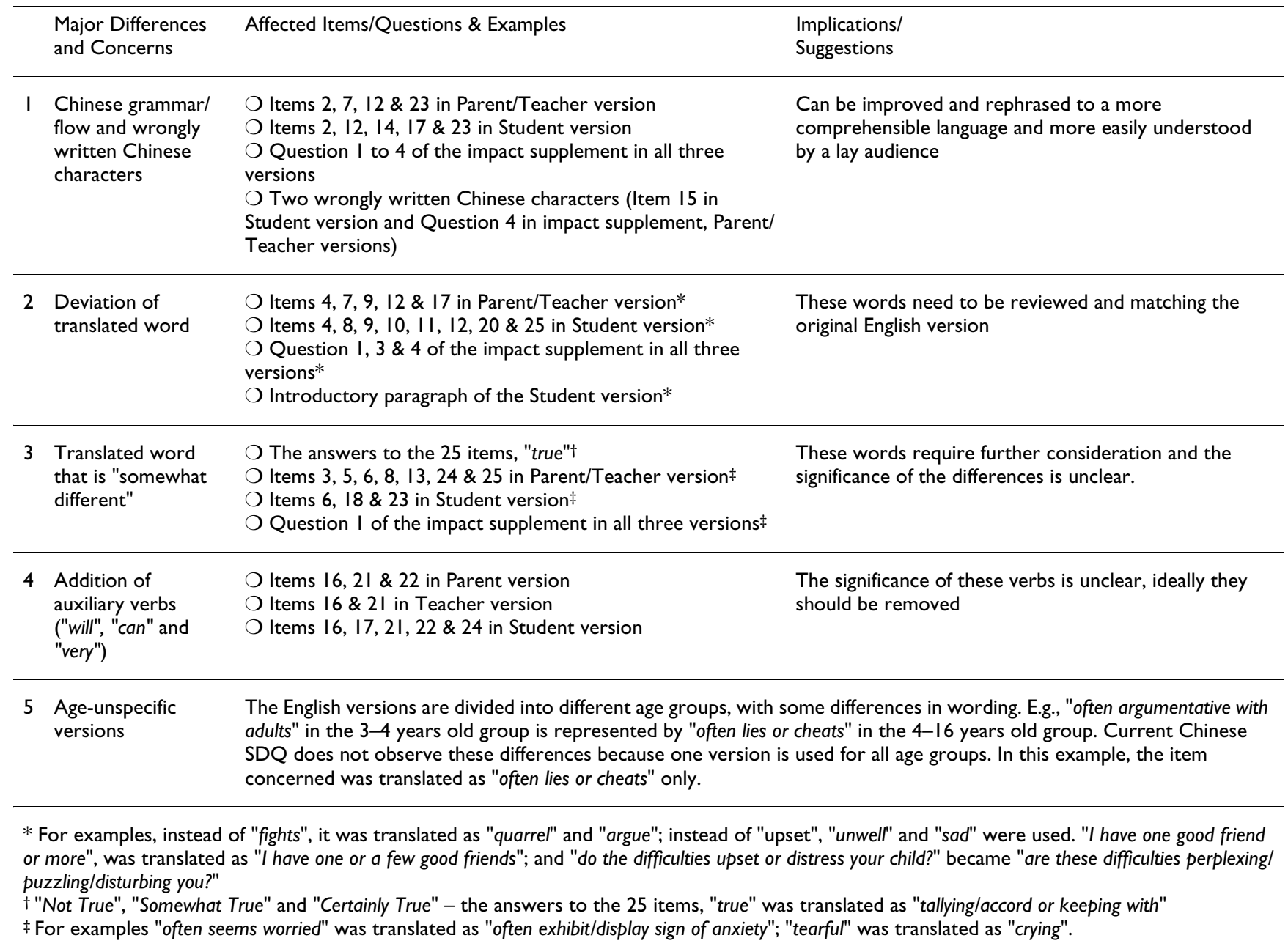

\section{Competing interests}

The authors declare that they have no competing interests.

\section{Authors' contributions}

Back-translation of the Chinese SDQ was performed by Toh TH and Ting TH. In addition all authors have contributed towards the writing and approval of this letter.

\section{Availability \& requirements http://www.sdqinfo.com/b3.html \\ http://www.sdqinfo.com/d4a.html}

\section{Additional material}

\section{Additional file 1}

Appendix A.

Click here for file

[http://www.biomedcentral.com/content/supplementary/1753-

2000-2-23-S1.doc]

\section{Additional file 2}

Appendix B.

Click here for file

[http://www.biomedcentral.com/content/supplementary/1753-

2000-2-23-S2.doc]

\section{Additional file 3}

Appendix $C$

Click here for file

[http://www.biomedcentral.com/content/supplementary/1753-

2000-2-23-S3.doc] 


\section{References}

I. Du Y, Kou J, Coghill D: The validity, reliability and normative scores of the parent, teacher and self report versions of the Strengths and Difficulties Questionnaire in China. Child Adolesc Psychiatry Ment Health 2(I8 [http://www.capmh.com/content/2/l/ 8]. $2008 \mathrm{Apr} 29$;

2. Goodman R: [http://www.sdqinfo.com]. (last modified 4/I I/0I)

3. Goodman R: The Strengths and Difficulties Questionnaire: A Research Note. Journal of Child Psychology and Psychiatry 1997, 38:58I-586.

4. Kou ], Du Y, Xia L: [Reliability and validity of "children Strengths and Difficulties Questionnaire" in Shanghai norm] [Abstract]. Shang Hai Jin Sheng Yi Xue (Shanghai Archives of Psychiatry) 2005, I:26-9 [http://www.cnki.com.cn/Article/C]FDTotalJSYI200501006.htm]. Chinese.

5. Crisante L, Ng S: Implementation and process issues in using Group Triple $\mathbf{P}$ with Chinese parents: Preliminary findings. Australian e-journal for the Advancement of Mental Health 2003, 2(3): [http://www.auseinet.com/journal/vol2iss3/crisanteng.pdf].

6. Leung C, Sanders MR, Leung S, Mak R, Lau J: An outcome evaluation of the implementation of the Triple P-Positive Parenting Program in Hong Kong. Fam Process 2003, Winter; 42(4):53I-44.

7. Cao F, Su L: Internet addiction among Chinese adolescents: prevalence and psychological features. Child: care, health and development 33(3):275-28I.

8. Huang $Y$, Gao X, Zhang XW, Xiang Y, Fu Y, Meng HQ, Ma XH, Wans YC, Sun X, Liu X, Li T: [Examining the comorbidity of attention deficit and hyperactivity disorder and conduct disorder in a population-based twin sample] [Abstract]. Zhonghua $Y_{i} X_{u e} Y_{i}$ Chuan Xue Za Zhi 2008, 25(I):23-6. Chinese.

9. Lai KYC: The Establishment of a Triage System in a Child and Adolescent Psychiatry Clinic in Hong Kong. Child and Adolescent Mental Health 2006, I I (4):204-207.

10. Gau SSF, Shang CY, Liu SK, Lin CH, Swanson JM, Liu YC, Tu CL: Psychometric properties of the Chinese version of the Swanson, Nolan, and Pelham, version IV scale - parent form. Int J Methods Psychiatr Res 2008, I7(1):35-44.

Publish with Bio Med Central and every scientist can read your work free of charge

"BioMed Central will be the most significant development for disseminating the results of biomedical research in our lifetime. "

Sir Paul Nurse, Cancer Research UK

Your research papers will be:

- available free of charge to the entire biomedical community

- peer reviewed and published immediately upon acceptance

- cited in PubMed and archived on PubMed Central

- yours - you keep the copyright
BioMedcentral 